\title{
Social Benefits and Income Inequality in Post-Socialist China and Vietnam
}

\author{
Qin Gao \\ Fordham University \\ aqigao@fordham.edu \\ Martin Evans \\ University of Oxford \\ martin.evans@socres.ox.ac.uk \\ Irwin Garfinkel \\ Columbia University \\ ig3@columbia.edu
}

An earlier version of this paper was presented at the conference on Asian Social

Protection in Comparative Perspective, 7-9 January 2009, National University of Singapore,

Singapore. 


\begin{abstract}
:
China and Vietnam have both experienced significant political, economic, and social changes during the past quarter century. Alongside such transitions has been the restructuring of their respective social benefit systems. Using recent national household survey data, this paper compares the sizes, structures, and progressivity of the social benefit systems in China and Vietnam and examines their impacts on income inequality. It also contrasts the urban and rural systems within and between the two countries. We find that the size of China's social benefit system, as measured by the share of social benefit income in total household income, was much larger than that of Vietnam, but the Vietnamese system was much more progressive than the Chinese system. Pensions and social welfare transfers were more prominent in Vietnam, while education benefits were more generous in China. The urban-rural gap in social benefit provision was much wider in China than in Vietnam: Chinese urban residents enjoyed significantly more benefits than their rural peers, while Vietnamese urban residents only had modest advantage over their rural peers. Based on these comparative analyses, implications for social policy developments in both countries are discussed.
\end{abstract}

Keywords: social benefits, income inequality, social policy, China, Vietnam 


\section{Introduction}

China and Vietnam share a border and much socialist ideology. During the past quarter century, they have both adopted pro-market economic reforms, resulting in a combination of rapid economic growth and significant poverty reduction. With an average annual GDP growth rate of 9.7 per cent since 1980, China "has had the largest and fastest poverty reduction in history” (World Bank 2008: 22). The World Bank estimates that the poverty rate in China fell from 64 per cent in 1981 to 7 per cent in 2007 using a “cost of basic needs” poverty line (World Bank 2008). Vietnam has also made remarkable progress since its economic reform was launched in 1986. Its annual GDP growth rate averaged 7.4 per cent since 1988 and maintained above 8 per cent since 2005. Poverty rate in Vietnam fell from 53 per cent in 1993 to 16 per cent in 2006 using consistent “cost of basic needs” measures derived by the World Bank. As two of the world's most successful transition economies, China and Vietnam continue to emphasize economic growth over other developmental goals.

Despite the many similarities, China and Vietnam have very different levels of economic and social developments. First, people in China enjoy a much higher level of real standard of living than those in Vietnam. Using the New 2005 Purchasing Power Parity (PPP) developed by the World Bank (World Bank 2008), per capita GDP in China was \$6,100 (US dollars) in 2008, while it was only \$2,900 in Vietnam (U.S. Central Intelligence Agency [CIA] 2009). Second, income inequality is much more prominent in China than in Vietnam. In 2004, the lowest income decile households in China only had 1.6 per cent of total income while the top decile had 34.9 per cent of total income. In contrast, these figures were 2.9 per cent and 28.9 per cent, respectively, in Vietnam (CIA 2009). 
Another important difference across China and Vietnam has been their commitment to and development of social benefits. Alongside China’s rapid economic growth has been the cutback of its social benefit system (Gao 2006; 2008). Yet rising income inequality and emerging social problems call for broader and stronger social protection (Gao and Riskin 2009). Vietnam took core decisions on economic reform later than China and thus can learn from the social and political problems resulted from China’s rapid growth. Indeed, policymakers in Vietnam have explicitly aimed to link growth with equality to avoid some of the severe urbanrural disparities and other rises in inequality that have developed during China's economic expansion (Evans and Harkness 2008).

In a recent conceptual analysis of the welfare regimes of China and Vietnam, London (2009) concludes that social policies and welfare in both countries are subordinate to economic development policies, despite that the governments of both countries have stated their commitments to universalism. However, the Vietnamese government has been more responsive to the welfare needs of its citizens as compared to the Chinese government. Consequentially, the Vietnamese welfare regime is more redistributive than the Chinese regime.

To provide empirical evidence on the social welfare developments in the two countries and to draw implications for their ongoing policy changes, this paper compares the sizes and structures of cash transfers in China and Vietnam using recent national household survey data. It also examines the impacts of cash transfers on income inequality and contrasts the urban and rural systems within and between the two countries.

Cash transfers are an important component of the social benefit system and typically include pensions, work-related social insurance, unemployment insurance, and public assistance. Another important component of the social benefit system is in-kind benefits, typically 
consisting health, education, and housing benefits. While these in-kind benefits are essential in supporting or improving the well-being of individuals and families, we are unable to include them in our empirical analysis due to unavailability or inconsistency of household survey data across the two countries.

\section{Social Benefit Systems in China and Vietnam: An Overview}

The Chinese Social Benefit System

Embedded in the fundamental structural distinctions between urban and rural China, the social benefit provision mechanisms differ substantially across the two areas. The urban social benefit system has undergone significant cutbacks from its comprehensive coverage and generous provision before the economic reforms, while the rural social benefit system has remained minimal (Gao 2006; 2008; Gao and Riskin 2009).

The urban social benefit system was an inherent part of the "full employment” policy in urban China before the economic reforms were launched in the late 1970s. Under the pre-reform regime, almost all working-age urban residents were employed in state-owned or collective enterprises and received various social benefits through their work units (Davis 1989; Guan 2000; Saunders and Shang 2001; Wong 1998). However, these social benefits have been much curtailed since the economic reforms, mainly to facilitate market restructuring and stimulate economic growth (Croll 1999; Gao 2006; Leung 2003).

The reforms of the urban social benefit system have focused on shifting the financing of social benefits from state-owned and collective enterprises to general taxes and individuals so that the enterprises can concentrate on increased production and efficiency. Housing, which was widely provided at low or no cost before the reforms, has been privatized. Food assistance, a major 
benefit to urban residents during the pre-reform period, has vanished. Pensions, health benefits, and other work-related social insurance (such as maternity, sickness, and industrial injury) have become to require individual contributions and have shifted to a wider risk pooling scheme across enterprises. Meanwhile, however, the government has taken a bigger and more direct role in providing a safety net for the very poor. Unemployment insurance and the Minimum Living Standard Assistance (MLSA), the major public assistance program, have been established and enforced since the early-to-mid 1990s to meet the basic needs of many that have been left behind by both the economic and welfare reforms (Gao 2006; Li and Piachaud 2004; Solinger 2002; Tang, Sha and Ren 2003).

The rural social benefits have always been marginal in coverage and minimal in provision, before and since the economic reforms (Gao 2008; Gao and Riskin 2009; Guan 2000; Saunders and Shang 2001). Only about 1.5 per cent of the rural residents have been privileged to have access to pensions due to their prior employment in state-owned or collective enterprises. Traditionally, there have been three safety-net programs in rural China. The "Five Guarantees" program has existed to provide for the rural elderly, disabled, and minors who had no family support or income sources to meet five basic needs: food, clothing, medical care, housing, and burial expenses. This system, however, has been ineffective in sufficiently serving the target population in many rural areas. Two other public assistance programs - the natural disaster relief system and the collective welfare fund - have also been in place, aiming to protect the vulnerable from natural disasters and human misfortunes (Guan 2000; Saunders and Shang 2001; Zhu 2002). Building on expansions of the urban MLSA and in an effort to address the inadequacy of the existing public assistance programs, the rural MLSA was established nationwide in 2007 after a series of provincial experiments. The rural MLSA aims to provide cash subsidies to poor 
families so that they can meet basic local living standards. The majority of the recipients have low income because of chronic illness, disability, old age, and/or an adverse natural living environment. The total number of rural MLSA recipients more than doubled from 16.1 million in January 2007 to 38.8 million in October 2008 (Ministry of Civil Affairs [MCA] 2008). Due to the lack of household survey data, this paper is unable to include an evaluation of the effectiveness of the rural MLSA.

Before the economic reforms, the Rural Cooperative Medical System (RCMS) provided basic health services and wide coverage to rural residents. It was jointly funded by family contributions, a portion of the collective welfare fund, and sometimes the government. However, this system collapsed after the economic reforms were lauched, leaving many rural residents unable to afford the dramatically increasing health care expenses (Bloom and Fang 2003; Liu 2004; Rösner 2004). To address this gap, the government has gradually restored the RCMS since the mid-1990s and has implemented it nationwide in 2008. The RCMS is a heavily subsidized voluntary health insurance program for rural residents. The government—central and local—is responsible for about 80 per cent of RCMS expenditures. The central government provides subsidies to the less developed provinces in the western and central areas. In 2008, the government contributed 80 yuan for each participant, whereas individuals only contributed 20 yuan. Although the coverage is 100 per cent in principle, it is important to note that actual beneficiaries were only about 30 per cent of all rural residents in 2007 (Mao 2008). Similarly, this paper is unable to include an evaluation of the effects of the RCMS due to household survey data unavailability.

The Vietnamese Social Benefit System 
One clear goal of the current Vietnamese government has been to improve social benefit coverage to its entire population. Although the term "universal” is used for this approach, it bears a very different meaning than in current European discussions, which use this term to denote forms of benefits that are provided based on certain circumstances with no test of income. Universalism in Vietnam refers to a wide and confusing range of provisions. The role of contributory social security is central, but the coverage from such provisions is only about one third of all working people, even with a rapidly expanding urban-based formally-employed workforce. The liabilities of the socialist era, however, are huge. Pensions for the cadres who were employed in government and state-owned enterprises have fully protected rights under the new contributory system based on their previous employment - for which there are no contributory records. This results in a large expenditure on pensions that remains a direct call on the state budget. The new cohorts of formally employed workers have contributory protection for maternity, sickness, industrial injury and health insurance under a separate scheme. A decision has been made to introduce unemployment insurance. This decision appears perverse for a number of reasons: the risk of unemployment is actually linked to circumstances that are not aligned to contributions - the young, those in informal employment, and those under-employed in the agricultural sector. Moreover, the funding of additional elements of contributory social insurance will raise contribution rates to 25 per cent and thus have an indirect effect on employment levels and the formalization of employment. Access to contributory pensions through voluntary social insurance has expanded greatly since 2004 and represents one element of the “universal” approach (World Bank 2007).

The health insurance system to assist in access to healthcare has developed alongside the process of health finance reform that saw the introduction of user-charges, purchaser-provider 
finance models and some privatization of hospital services, all of which was strangely termed "socialization.” The universal approach for healthcare firstly provides automatic free access to all children aged five and younger, those who qualify for war disablement and survivors benefits, and the very few that receive the basic social assistance safety net (World Bank 2007, Evans et al. 2007). Voluntary health insurance has been introduced to all school children (although in the mixture of commune level charges and obligations it is often difficult to describe as "voluntary" in practice) and to the remainder of the population. Uptake of voluntary health insurance has been high but has suffered from adverse selection with the elderly and most ill often having their contributions paid by younger and fitter family members. The combination of the erosion of primary healthcare provision and referral and the selective uptake of healthcare by those with insurance coverage has led to a crisis in health insurance funds and healthcare finance.

Non-contributory transfers exist for two main groups. First, the war veterans, disabled and survivors of those killed in the long wars of independence receive a mix of cash transfers and benefits in kind (such as housing support and healthcare). Members of this group are largely older persons and form a cohort who will age out of social protection over the next decade or more. However, there is also a younger cohort who have suffered from congenital handicap as a result of dioxin (Agent Orange) exposure from long-term environmental pollution from U.S. munitions and stores from the 1970s. The second group receive a small range of categorical means-tested social assistance. Eligibility for this group include being disabled, aged over 85, orphaned, or suffering from HIV/AIDS and having income below the official poverty line. Additionally, Viet Nam provides cash transfers to offset the impact of user-charges for healthcare and education for some low income groups, such as poor elderly people for healthcare, and in geographically targeted areas that are remote and with poor infrastructure and high 
numbers of disadvantages ethnic minority groups. These transfers, particularly transfers that help with healthcare costs are very important in areas of the country where coverage by social insurance pensions are low. Indeed, in areas such as the Mekong Delta and other regions of South Viet Nam, such transfers make up the largest element of the social protection package (Evans et al 2007).

\section{Data and Methods}

Data

We use two recent national household survey datasets to conduct the analyses: the China Household Income Project 2002 survey (CHIP) and the Vietnam Household Living Standards 2004 Survey (VHLSS). CHIP is a national, cross-sectional study designed by a team of Chinese and Western scholars and conducted by the Institute of Economics at the Chinese Academy of Social Sciences. Thus far, three waves of data have been collected, in 1988, 1995, and 2002. Samples of the CHIP study were drawn from larger National Bureau of Statistics samples using a multistage, stratified probability sampling method. With sample provinces from eastern, central, and western regions of China, the CHIP study is nationally representative and arguably the best publicly available data source on Chinese household income and expenditures (Khan and Riskin, 2005; Riskin, Zhao and Li, 2001). The 2002 CHIP urban surveys contain 6,835 households or 20,632 individuals, while the rural surveys include 9,200 households or 37,968 individuals.

VHLSS is carried out by the Vietnam General Statistical Office and collects data on living conditions in households across Vietnam. The 2004 survey is the second of a planned bi-annual survey project spanning 2002 to 2010. The VHLSS sample households were randomly selected from a commune register including representative samples of communes from all provinces and 
regions. The effective sample size for VHLSS 2004 survey is 9,140 households containing 40,359 individuals (Evans et al., 2007).

It is important to note that analyses in this paper exclude the migrants in both countries. Since the mid-1990s, rapid economic growth in both China and Vietnam has led to significant levels of migration, mainly from rural to urban areas but also between rural areas. Given the drastically rising sizes of the migrant population in both countries, this exclusion is a huge omission. More specifically, because most migrants are either ineligible for or not actual beneficiaries of social benefits, excluding migrants would most likely overestimate the size of total social benefits; because the average incomes of migrants remain much lower than those among the urban residents, ${ }^{1}$ the regressivity of social benefits would most likely to be underestimated due to the exclusion of the migrants.

In China, the number of migrants jumped from 18 million in 1989 to 70 million in 1993 and to 150 million by 2004 (Liang 2001; Zhu and Zhou 2005). Migrants now make up 11 percent of the national population and more than 20 percent of urban residents. However, migrants receive virtually no social benefits. They usually do not qualify for rural benefits because they are of working age with earning capabilities. Meanwhile, they are not entitled to any urban social benefits due to the lack of registered local city resident status. In 2002, less than 5 per cent of migrants received any pensions, unemployment insurance, or health benefits (Gao 2006). In fact, the taxes and fees they paid exceeded the subsidies they received (Khan and Riskin 2005).

Vietnam has also had large and mostly unmeasured migration into urban areas. Current evidence from a range of surveys show inflows and outflows from selected urban and rural areas respectively (GSO and UNFPA 2004; Le and Nguyen 1999), but the true extent of migration and

\footnotetext{
${ }^{1}$ For example, in China, the average migrant household's income was only two thirds of that among those with urban registration status in 2002 (Khan and Riskin 2005).
} 
reliable estimates of populations will only be apparent with the publication of the 2009 Census. The VHLSS sample was constructed using administrative commune-based records of registered households. Therefore, the "unregistered” households are missing from VHLSS. The growing migrant population in Vietnam are mostly "unofficial” and do not have official registration status in the destination communes. While registration is supposed to limit migration without official sanction, the actual effect is to establish significant populations that are extra-legally resident. A migration survey conducted in 2004 estimated that more than 50 per cent of migrants living in renting houses are unregistered. Further, many migrants do not live in private households but rather in dormitories or other group residential accommodations. Therefore, they are excluded from the survey. Similar to migrants in China, the lack of official registration status also prevent the Vietnamese migrants from access to government transfers and services. However, there is to date no accurate estimation of the level of social benefits received by the Vietnamese migrants.

\section{Measures and Methods}

We adopt a comprehensive measure of total household per capita income, which includes market income, cash and in-kind social benefits, and private transfers. Market income includes the sum of individual earnings from waged employment and all other income sources from the market such as income from private enterprises, property income, and income from family farming and non-farm activities. Tax payments and any social security contributions are deducted.

Social benefits are composed of cash transfers and in-kind benefits. Cash transfers include social insurance and social welfare income and in Viet Nam, transfers to offset user charges for health and education, while in-kind benefits include education and health services in China. Education benefits were not directly asked in the CHIP surveys. We impute households' 
education benefits in China by assigning the average government per capita spending on education for students enrolled in schools when surveyed. Such imputations are done by education level (i.e., elementary, junior high, and senior high schools, respectively) and by urban and rural areas. The imputation can help understand the overall level of education benefits in China in comparison to Vietnam. However, because it is based on mean per capita government spending, it may lead to underestimation of inequality of the distribution of education benefits in China. Meanwhile, education benefits surveyed in VHLSS included government supports on tuition fees, school materials, and scholarships. Two other types of important in-kind benefits housing and food - were only surveyed in CHIP but not VHLSS. We do not have reliable Vietnamese administrative data to simulate these benefits, therefore they are excluded from this comparative study. ${ }^{2}$

The first task of this study is to compare the sizes and structures of the social benefit systems in China and Vietnam. The proportion of the social benefit package in total household income reflects the generosity of a nation's social welfare provision. Further, certain social benefit programs, such as pensions or education, may have more generous benefits and broader coverage than others, revealing a nation's priorities in addressing the social needs of various subgroups. To examine which specific social benefits play a more predominant role across the two countries, we examine the differences in the structures of their social benefit packages by comparing the proportions of each benefit in the total benefit package.

The second task of this study is to compare the impacts of the social benefit systems on income inequality across China and Vietnam. An explicit redistributive mechanism, the social benefit system reallocates resources to improve the economic well-being of certain subgroups as

\footnotetext{
${ }^{2}$ Based on authors' calculation, in 2002, housing benefit made up 1.6 per cent and food assistance made up 0.3 per cent of total household income for Chinese families on average.
} 
well as the overall social justice. We compare the allocation of social benefits - both total and specific - across income quintiles of China and Vietnam. The higher the proportion of social benefits received by lower income quintiles, the more progressive the social benefit system. We further examine whether and to what extent the income redistribution through social benefit transfers raised or reduced the overall income inequality. This is achieved by comparing pre- and post-transfer income inequality levels. Four different inequality measures are used to capture the impacts of social benefits on income inequality. First, we use the Gini Coefficient, which reflects overall income distribution and is the most widely used measure of inequality. Second, we use the ratio of incomes of those at the $90^{\text {th }}$ and $10^{\text {th }}$ percentiles (hereafter P90/P10 ratio) to show the relative income distance between the top and bottom of the income distribution. Third, to reveal whether social benefits affect the top and bottom of the income distribution differently, we adopt two additional inequality measures: the ratio of incomes of the $90^{\text {th }}$ to $50^{\text {th }}$ percentile (hereafter P90/P50 ratio) which measures the top of the distribution and the ratio of incomes of the $50^{\text {th }}$ to $10^{\text {th }}$ percentile (hereafter P50/P10 ratio) which measures the bottom of the distribution (Garfinkel, Rainwater and Smeeding 2006).

\section{Size of Social Benefits and Urban-Rural Contrast}

Measured by the share of social benefits in total household income, the size of China's social benefit system was much larger than that of Vietnam. As shown in Table 1, in 2002, social benefits made up 19 per cent of total household income in China. ${ }^{3}$ On the contrary, in 2004, social benefits on average were only 4 per cent of Vietnamese families’ household income. Market income and private transfers played different roles in China and Vietnam. Market income comprised a larger proportion of total household income in Vietnam (86 per cent) than in China

\footnotetext{
${ }^{3}$ This, however, could be an overestimation - especially in comparison to Vietnam - due to the imputation of education benefits specified above. Next steps of this research will try omitting education benefits from the social benefit package and see how it can affect the analysis result.
} 
(79 per cent). Private transfers were a much more significant component in Vietnam (10 per cent of total household income) than in China (2 per cent).

[Table 1 about here]

The urban-rural gap in social benefit provision was much wider in China than in Vietnam: Chinese urban residents enjoyed significantly more benefits than their rural peers, while Vietnamese urban residents only had modest advantage over their rural peers. In urban China, social benefits on average made up slightly more than a quarter of total household income. On the contrary, the proportion of social benefits in total household income in rural China was only 6 per cent. To further illustrate this huge urban-rural gap, Figure 1 contrasts the population shares and the proportions of total social benefits received by urban and rural households. In 2002, the rural population made up 61 per cent of the national population, but they only enjoyed 10 per cent of total national social benefits. In Vietnam, the proportion of social benefits in total household income was was similar in the two areas (i.e., 4.8 per cent in urban areas and 4.0 per cent in rural areas).

[Figure 1 about here]

The roles of market income and private transfers were also different by urban and rural residency in both countries. As shown in Table 1, the share of market income in total household income was larger in rural areas than in urban areas in both countries. However, this difference is more prominent in China (91.8 per cent in rural areas relative to 72.8 per cent in urban areas) than in Vietnam (87.1 per cent in rural areas relative to 84.3 per cent in urban areas). The same pattern holds for private transfers: in China, private transfers contributed more to total household income in rural areas (2.3 per cent) than in urban areas (1.6 per cent), while in Vietnam, private 
transfers played a larger role in urban areas (10.9 per cent of total household income) than in rural areas (8.9 per cent).

\section{Composition of the Social Benefit Systems and Urban-Rural Difference}

Both the Chinese and Vietnamese social benefit systems were dominated by pensions and supplemented by work-related social insurance and welfare assistance. As shown in Figure 2, pensions made up about half of total social benefits in China and almost two-thirds of total social benefits in Vietnam. However, social welfare played a much more prominent role in Vietnam than in China: 9.2 per cent of total social benefits in Vietnam were from social welfare while the corresponding proportion was only 1.6 per cent in China. Work-related social insurance benefits were marginal in both countries, making up 2.7 per cent of total social benefits in China and 1.6 per cent in Vietnam.

[Figure 2 about here]

With regard to in-kind benefits and cash off-sets for user-charges, China and Vietnam had similar levels of health benefit provision, but education benefits were more generous in China than in Vietnam, partly because of measurement problems for in-kind education subsidies in Vietnam. More specifically, health benefits made up about 23 per cent of total social benefits in both countries. Education benefits comprised 23.5 per cent of total social benefits in China but only 4.8 per cent in Vietnam. This, however, might be due to the overestimation of Chinese education benefits yielded by the simulation using administrative data and possibly the underestimation of Vietnamese education benefits resulted from the limited number of questions asked in the VHLSS.

Similar to the size of social benefit provision, the urban-rural difference in social benefit structure was also much sharper in China than in Vietnam as is evident in Table 2. Nearly 60 per 
cent of social benefits in urban China were from comparably consistent cash transfers, while the rural residents only had 6.7 per cent of total social benefits in the form of cash transfers. More specifically, pensions were very generous in urban China, making up 53.9 per cent of total social benefits, but they constituted only 6.2 per cent of rural social benefits. Rural residents did not benefit from any work-related social insurance income, while urban residents had 3 per cent of their social benefits from this source. Social welfare was also more generous in providing a safety net for the urban poor than for their rural peers, making up 1.7 per cent of total urban social benefits and only 1 per cent of total rural social benefits. Health benefits also favored the urban residents, providing slightly more than a quarter of total social benefits, while rural residents only had 0.5 per cent of their social benefits from health care. Education was the only predominant rural social benefit that made up more than 90 per cent of their total social benefits, relative to 15.7 per cent in urban areas. However, it is important to remind that the size of the rural social benefit system was much smaller than the urban one as presented above, and thus the seemingly large 90 per cent actually only corresponded to 5.6 per cent in total rural household income.

\section{[Table 2 about here]}

The urban-rural disparity in the structure of social benefits was much smaller in Vietnam than in China. The majority of social benefits were from cash transfers in both urban and rural Vietnam, making up 79 per cent and 73 per cent of total social benefits, respectively. Among the cash transfers, pensions dominated in both urban and rural areas, representing 73 per cent and 57 per cent of total social benefits, respectively. Notably, social welfare played a much larger role in rural Vietnam, making up 14 per cent of total social benefits, relative to only 4 per cent in urban areas. Health benefits were the major in-kind transfers, making up 18 per cent and 25 per cent of 
total social benefits in respective urban and rural areas. Education benefits were marginal in both areas, accounting for 3 per cent of total urban social benefits and 5 per cent of total rural social benefits.

\section{Distribution of Social Benefits: Progressive or Regressive?}

Overall, the social benefit systems in China and Vietnam were both regressive, as measured by the shares of total social benefits received by income quintiles. However, the regressivity in China was much more severe than in Vietnam, as illustrated in Figure 3. In both countries, social benefits did not favor the poor but rather increasingly rewarded the higher income groups. In Vietnam, the poorest income quintile enjoyed 6.6 per cent of all social benefits while the top quintile received almost 40 per cent of all social benefits. This gap between the rich and the poor was larger in China, where the lowest income quintile only enjoyed 2.5 per cent of all social benefits while about two-thirds of all social benefits went to the richest income quintile.

[Figure 3 about here]

The high regressivity of the Chinese social benefit system was driven by the drastically uneven provisions in urban and rural benefits as well as the much more regressive distribution of urban social benefit system compared to the rural system. Because the vast majority of social benefits (nearly 90 per cent as shown in Figure 1) in China were received by urban residents and the overall income level of urban residents was more than three times that of rural residents, the higher income quintiles in China were predominately from urban areas and thus enjoyed much more social benefits than the lower income groups. Further, urban social benefits were distributed much more regressively than the rural benefits, as illustrated in Figure 4. The top 
income quintile in urban China received more than half of all urban social benefits, while the top income quintile in rural China only enjoyed 27.5 per cent of all rural social benefits.

[Figure 4 about here]

In contrast, the urban-rural differences in social benefit provision and their distribution across income quintiles in Vietnam was much smaller, contributing to the lesser severity in regressivity in the Vietnamese social benefit system relative to the Chinese system. ${ }^{4}$

[Figure 5 about here]

Among the social benefits, health assistance, work-related social insurance, and pensions were the most regressive while social welfare was the least regressive in both countries. In China, as illustrated in Figure 6, the richest income quintile enjoyed 93 per cent of all health benefits, 76 per cent of all work-related social insurance, and 69 per cent of all pensions. In Vietnam, as shown in Figure 7, the top income quintile received 68 per cent of all work-related social insurance, 47 per cent of total pensions, and 45 per cent of all health benefits. Social welfare favored the lower income groups in both countries and particularly so in Vietnam, serving its safety net function. In China, education benefits were more progressive than social welfare, but still disproportionately favored the top two income quintiles.

[Figures 6 and 7 about here]

\section{Impact of Social Benefits on Income Inequality}

Social benefits played different roles in affecting overall income inequality in the two countries. In Vietnam, social benefits reduced overall income inequality, but the Chinese social benefit system increased overall income inequality due to its much more regressive relative to the Vietnamese system. Table 3 presents the impact of social benefits on income inequality using

\footnotetext{
${ }^{4}$ We have not yet got the exact results on this. We will present these results in Figure 5 and discuss them in text as soon as we finish the analyses.
} 
the four inequality measures described earlier. Compared to the inequality level based on the income definition of market income plus private transfers, the inclusion of social benefits in China lifted the overall income inequality level to a Gini Coefficient of 0.465 (from 0.450), an increase of 3.1 per cent, and a P90/P10 ratio of 8.489 (from 8.271), an increase of 2.6 per cent. On the contrary, the Vietnamese income inequality level was reduced to a Gini Coefficient of 0.401 (from 0.408), a decrease of 1.7 per cent, and a P90/P10 ratio of 6.172 (from 6.288), an decrease of 1.8 per cent, by social benefit transfers.

Did social benefits affect the top and the bottom of the income distributions differently? Social benefits in China enlarged the income inequality gap at the top of the income distribution (by 3 per cent) but reduced income inequality at the bottom (by 0.3 per cent). Therefore, the disequalizing impact of social benefits in China was largely driven by the favorable transfers to the richer income groups. The Vietnamese social benefit system, however, reduced income inequality at both the top (by 0.4 per cent) and the bottom (by 1.4 per cent) of the income distribution. These results again manifest that social benefits were distributed more regressively in China than in Vietnam.

\section{Conclusion and Discussion}

Using recent national household survey data, this paper compares the sizes, structures, and progressivity of the social benefit systems in China and Vietnam and examines their impacts on income inequality. It also contrasts the urban and rural systems within and between the two countries. We find that the size of China's social benefit system, as measured by the share of social benefit income in total household income, was much larger than that of Vietnam, but the Vietnamese system was much more progressive than the Chinese system. Pensions and social welfare transfers were more prominent in Vietnam, while education benefits were more generous 
in China, in part because we cannot measure the in-kind values of Vietnamese education provision. The urban-rural gap in social benefit provision was much wider in China than in Vietnam: Chinese urban residents enjoyed significantly more benefits than their rural peers, while Vietnamese urban residents only had modest advantage over their rural peers.

Based on these comparative results, the two countries can learn from each other to enhance their future social policy developments. China can draw policy implications from the Vietnam case in three respects. First, the progressivity of the Chinese social benefit system needs to be improved. As the Chinese government strives for a "Harmonious Society," a more equalizing distribution of resources is essential to provide some basic security to those left behind by both market development and social policy changes. It is also important for ensuring social stability and avoiding social unrest as China continues to prioritize economic growth among other developmental goals. Second, the huge urban-rural disparity needs to be addressed. Several recent government initiatives have begun to fill in this gap. These include eliminating agricultural taxes, restoring the rural RCMS, free compulsory education to rural and migrant children, and expanding MLSA and other public assistance programs to support the rural poor. The outcomes of these initiatives, especially their redistributive effects, require close observation and await evaluations. Third, certain social benefits, such as pensions and social welfare, can play a larger role in supporting Chinese families as the aging trend persists and the income inequality gap widens.

The Vietnamese social benefit system can also draw lessons form the Chinese case, at least in the following two regards. First, the overall size of the Vietnamese social benefit system needs to be enlarged, especially as the government strives for "universal coverage.” The current level of social benefit provision (i.e., only 4.3 per cent in total household income) is much lower 
than the levels in most advanced industrialized countries (i.e., 20 per cent or more ${ }^{5}$ ) and many transitioning and/or developing countries ${ }^{6}$. Second, education benefits appear to be very limited based on estimates in this study. This could be a reflection of the actual provision, but could also be due to the estimation method used. Further research needs to achieve a clear and accurate estimation of this important benefit. If indeed education benefits are at such a low level, the Vietnamese government needs to broaden its coverage and improve its benefit level to serve the nation’s future generations.

Some common challenges emerge for both China and Vietnam to address in their developments of social policies. First and most important, the two systems are both quite regressive, favoring the high income groups and ignoring the low income groups in redistributing resources through social benefit transfers. This is, on the one hand, divergent from their socialist ideologies, and on the other, a possible deterrence for their continued economic development. Social benefits need to play larger and more progressive roles in both countries. Second, as mentioned earlier, both countries have increasing numbers of migrants who are almost entirely uncovered by the current social benefit systems. This is a serious lack of respect to the migrants' basic human rights and may also be a source of social unrest. The absence of social protection for this group needs to be addressed.

\footnotetext{
${ }^{5}$ Measured as the percentage of total social benefit expenditure in GDP. Source: Garfinkel, Rainwater and Smeeding, 2006.

${ }^{6}$ We will get evidence from LIS to support this.
} 


\section{References}

Asian Development Bank (2004). Poverty Profile of the People’s Republic of China. Manila. Available online at http://www.adb.org/Documents/Reports/Poverty_Profile_PRC/PRC.pdf.

Bloom, G. \& J. Fang. 2003. China's rural health system in a changing institutional context. Institute of Development Studies Working Paper No. 194. Brighton, U.K.

Carrin, G., A. Ron, H. Yang, et al., 1999. The reform of the rural cooperative medical system in the People's Republic of China: Interim experience in 14 pilot counties. Social Science \& Medicine 48(7): 961-972.

Croll, E. J. 1999. Social welfare reform: Trends and tensions. China Quarterly 159: 684-699.

Davis, D. 1989. Chinese social welfare: Policies and outcomes. China Quarterly 119: 577-597.

Evans, Martin, Ian Gough, Susan Harkness, Andrew McKay, Huyen Dao Thanh and Ngoc Do Le Thu (2007). How Progressive is Social Security in Vietnam? UNDP Policy Dialogue Paper.

Evans, Martin and Susan Harkness (2008). Social protection in Vietnam and obstacles to progressivity. Asian Social Work and Policy Review 2(1): 30-52.

Gao, Q. 2006. The social benefit system in urban China: Reforms and trends from 1988 to 2002. Journal of East Asian Studies 6(1): 31-67.

Gao, Qin (2008). The Chinese social benefit system in transition: Reforms and impacts on income inequality. Annals of the New York Academy of Sciences, Vol. 1136: 342-347.

Gao, Qin and Carl Riskin (2009). Explaining China’s changing inequality: Market vs. social benefits. In Davis, D. and Wang, F. (eds), Creating Wealth and Poverty in Contemporary China. Stanford University Press. Palo Alto, CA. 
Garfinkel, Irwin, Lee Rainwater and Timothy Smeeding (2006). A re-examination of welfare states and inequality in rich nations: How in-kind transfers and indirect taxes change the story. Journal of Policy Analysis and Management, 25(4): 897-918.

GSO and UNFPA (General Statistics Office and United Nations Population Fund, 2004). The 2004 Viet Nam Migration Survey: Major findings. Statistical Publishing House. Vietnam.

Guan, X. 2000. China’s social policy: reform and development in the context of marketization and globalization. Social Policy \& Administration 34(1): 115-130.

Khan, Azizur Rahman and Carl Riskin (2005). China’s Household Income and its Distribution, 1995 and 2002. The China Quarterly 182, pp. 356-384.

Le, M. T. and Nguyen, D. V. (1999). Remittances and the Distribution of Income. pp. 167-181 in Haughton, Dominique, et al (eds.) Health and Wealth in Vietnam - an Analysis of Household Living Standard. Institute of Southeast Asian Studies, Singapore.

Leung, J. C. 2003. Social security reforms in China: Issues and prospects. International Journal of Social Welfare 12: 73-85.

Li, B. \& D. Piachaud. 2004. Poverty and Inequality and Social Policy in China. London: Centre for Analysis of Social Exclusion, London School of Economics. http://sticerd.lse.ac.uk/dps/case/cp/CASEpaper87.pdf.

Liang, Zai (2001). The age of migration in China. Population and Development Review 27(3): 499-524.

London, Jonathan (2009). Welfare Regimes in the Wake of State Socialism: Viet Nam, China, and the Market-Leninist Welfare Regime. Paper presented at the conference on "Asian Social Protection in Comparative Perspective," 7-9 January 2009, Singapore. 
Liu, Y. 2004. Development of the rural health insurance system in China. Health Policy and Planning 19(3): 159-165.

Ministry of Civil Affairs [MCA] (2008). Monthly Administrative Data on MLSA. MCA Department of Planning and Finance, available online at http://cws.mca.gov.cn/article/tjsj/dbsj/ (accessed on December 8, 2008).

Ravallion, M. and S. Chen (2007). China’s (Uneven) Progress Against Poverty. Journal of Development Economics 82: 1-42.

Riskin, Carl, Renwei Zhao and Shi Li (2001). China's Retreat from Equality: Income Distribution and Economic Transition. M. E. Sharpe, Inc. Armonk, NY.

Rösner, H. J. 2004. China’s health insurance system in transformation: Preliminary assessment, and policy suggestions. International Social Security Review 57(3): 65-90.

Saunders, P. \& X. Shang. 2001. Social security reform in China's transition to a market economy. Social Policy \& Administration 35(3): 274-289.

Solinger, D. J. 2002. Labour market reform and the plight of the laid-off proletariat. China Quarterly 170: 304-326.

Tang, J., L. Sha \& Z. Ren. 2003. Zhongguo Chengshi Pinkun yu Fanpinkun Baogao (Report on Poverty and Anti-Poverty in Urban China). Huaxia Press. Beijing, China.

Wong, L. 1998. Marginalization and Social Welfare in China. Routledge/ London School of Economics. London; New York.

World Bank (2007). Social Protection: Vietnam Development Report 2008. Hanoi: World Bank. World Bank (2008). China Quarterly Update, February 2008. Available online at http://siteresources.worldbank.org/INTCHINA/Resources/3188621121421293578/cqu_jan_08_en.pdf. Accessed on August 19, 2008. 
Zhu, Y. 2002. Recent developments in China's social security reforms. International Social Security Review 55(4): 39-54.

Zhu, Y. and Zhou, T. (2005). Total number of migrants doubled within 10 years, making up more than 10 per cent of total population. Xinhua Net, as cited in China Net, available online at http://www.china.org.cn/chinese/renkou/748584.htm, accessed on 25 October, 2006. Beijing, China. 
Table 1: Composition of Household Income in China and Vietnam (\%)

\begin{tabular}{lrrr|rrr}
\hline & \multicolumn{3}{c|}{ China 2002 } & \multicolumn{3}{c}{ Vietnam 2004 } \\
\cline { 2 - 7 } & National & Urban & Rural & National & Urban & Rural \\
\hline Market Income & 79.0 & 72.8 & 91.8 & 86.0 & 84.3 & 87.1 \\
Social Benefits & 19.2 & 25.6 & 6.0 & 4.3 & 4.8 & 4.0 \\
Private Transfers & 1.8 & 1.6 & 2.3 & 10.0 & 10.9 & 8.9 \\
\hline Total household income & 100.0 & 100.0 & 100.0 & 100.0 & 100.0 & 100.0 \\
\hline
\end{tabular}

Table 2: Composition of Social Benefits in China and Vietnam by Urban-Rural Residence (\%)

\begin{tabular}{lrrr|rrr}
\hline & \multicolumn{3}{c|}{ China 2002 } & \multicolumn{3}{c}{ Vietnam 2004 } \\
\cline { 2 - 6 } & National & Urban & Rural & National & Urban & Rural \\
\hline Cash Transfers & 53.4 & 58.7 & 6.7 & 72.6 & 79.4 & 72.5 \\
Social Insurance - Pensions & 49.1 & 53.9 & 6.2 & 61.8 & 73.0 & 57.3 \\
Social Insurance - Work-related & 2.7 & 3.0 & 0.0 & 1.6 & 2.0 & 1.4 \\
Social Welfare & 1.6 & 1.7 & 1.0 & 9.2 & 4.4 & 13.8 \\
In-kind (Ch) \& Cash Benefits (Vn) & 46.6 & 41.3 & 93.3 & 27.4 & 20.6 & 27.5 \\
Education & 23.5 & 15.7 & 92.8 & 4.8 & 3.2 & 4.9 \\
Health & 23.0 & 25.6 & 0.5 & 22.6 & 18.4 & 22.4 \\
\hline Total Social Benefits & 100.0 & 100.0 & 100.0 & 100.0 & 100.0 & 100.0 \\
\hline
\end{tabular}

Table 3: Impact of Social Benefits on Income Inequality in China and Vietnam

$\begin{array}{lllll}\text { (a) (b) } & \text { (c) } & \text { (d) } & \text { (c)-(b) }\end{array}$

Market Income + Private Transfers + Social Benefits - Taxes (b)

China 2002

Overall Inequality

$\begin{array}{lllll}\text { Gini Coefficient } & 0.452 & 0.450 & 0.465 & 0.463+3.1 \%\end{array}$

$\begin{array}{lllll}\text { P90/P10 Ratio } & 8.265 & 8.271 & 8.489 & 8.448+2.6 \%\end{array}$

Top of Distribution

$\begin{array}{lllll}\text { P90/P50 Ratio } & 3.176 & 3.156 & 3.252 & 3.199\end{array}$

Bottom of Distribution

P50/P10 Ratio

Vietnam 2004

Overall Inequality

Gini Coefficient

P90/P10 Ratio

0.409

0.408

6.288

0.401

6.172

Top of Distribution

P90/P50 Ratio

6.345

2.697

2.687

$2.665-0.4 \%$

Bottom of Distribution

P50/P10 Ratio

2.387

2.331

2.299

$2.288-1.4 \%$ 
Figure 1:

Contrast between Population Share and Social Benefit Share in Urban vs. Rural China

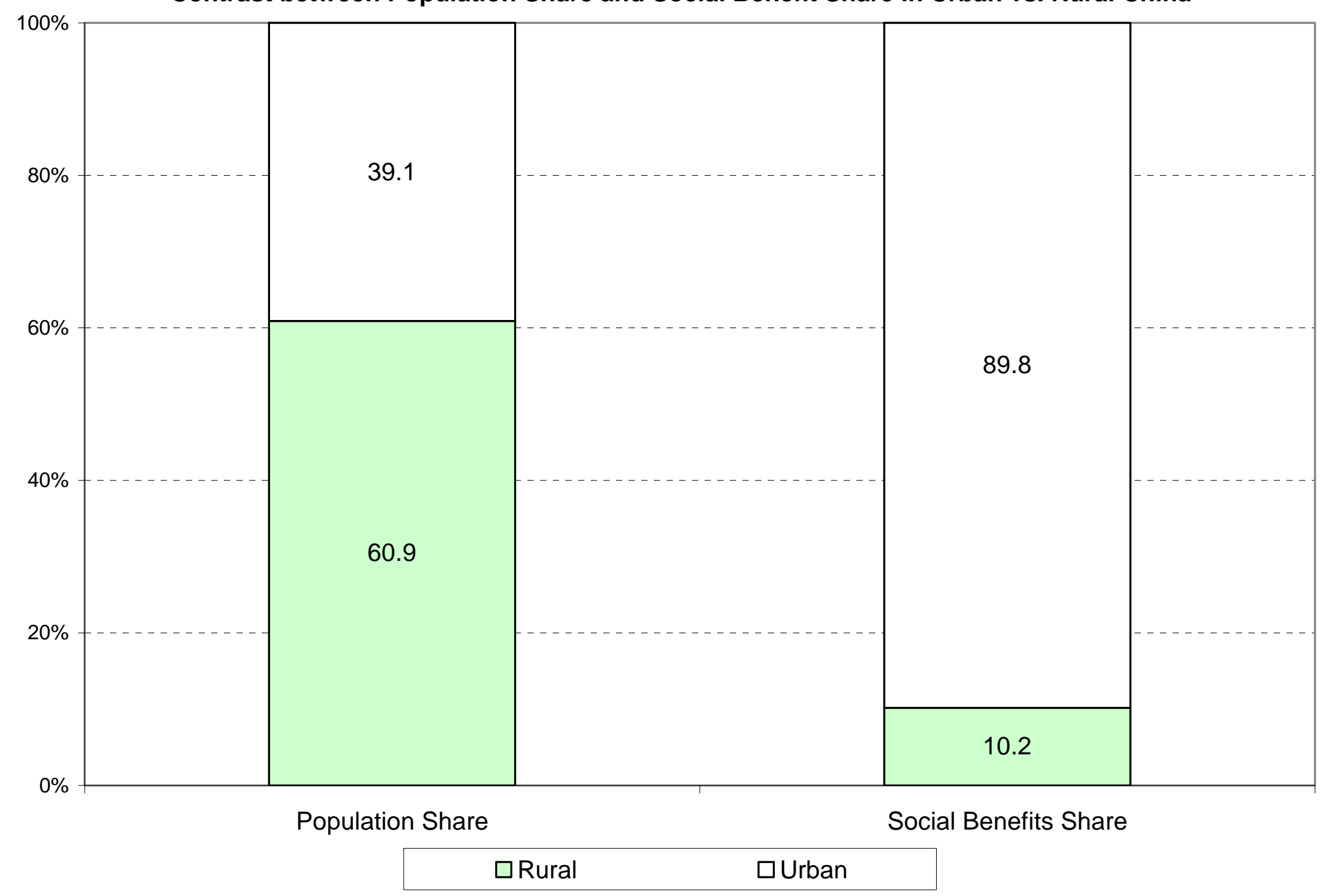


Figure 2: Composition of Social Benefits in China and Vietnam (\%)

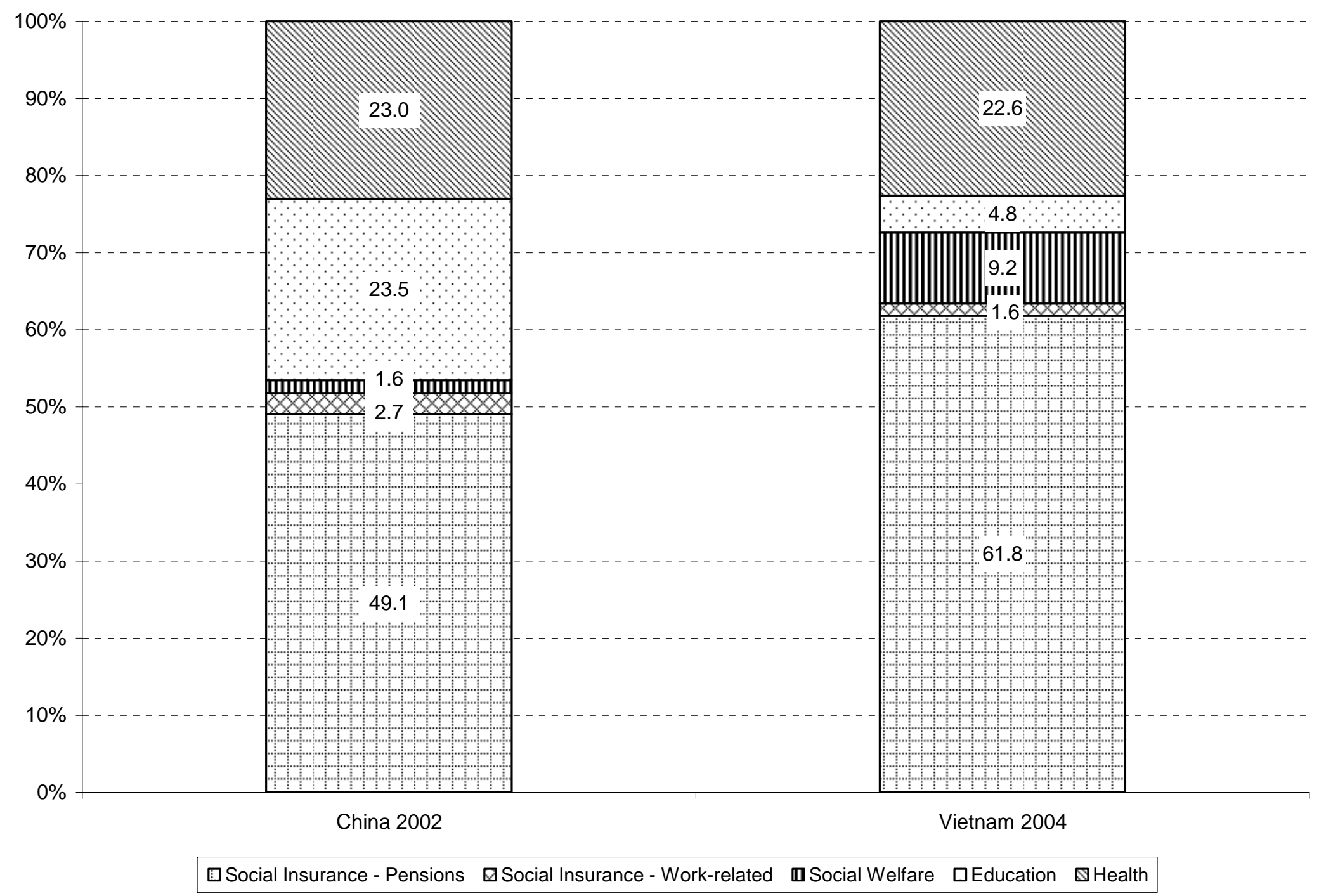


Figure 3: Shares of Social Benefits Received by Income Quintiles in China and Vietnam (\%)

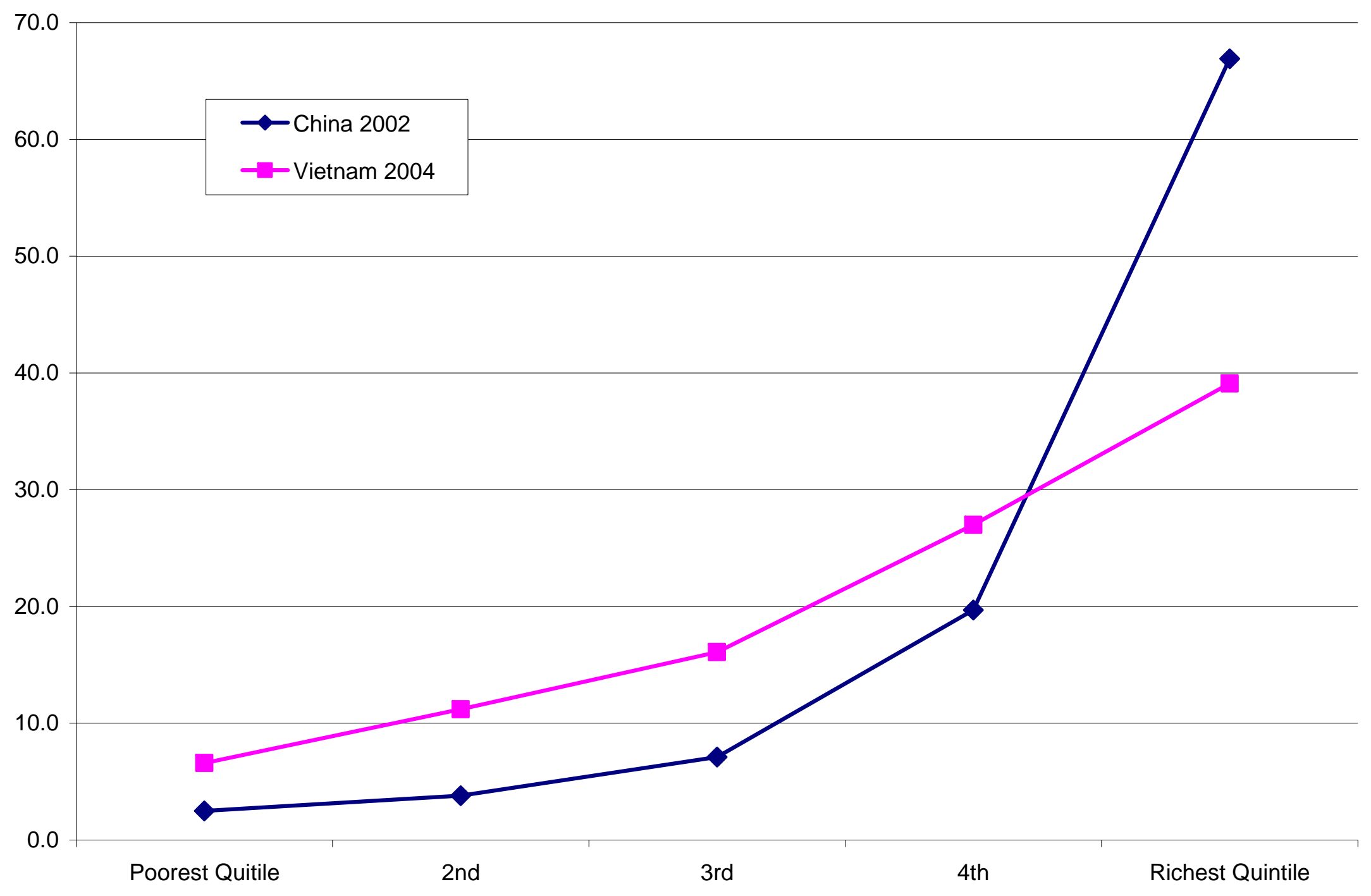


Figure 4:

Shares of Social Benefits Received by Income Quintiles in China By Urban-Rural Residence (\%)

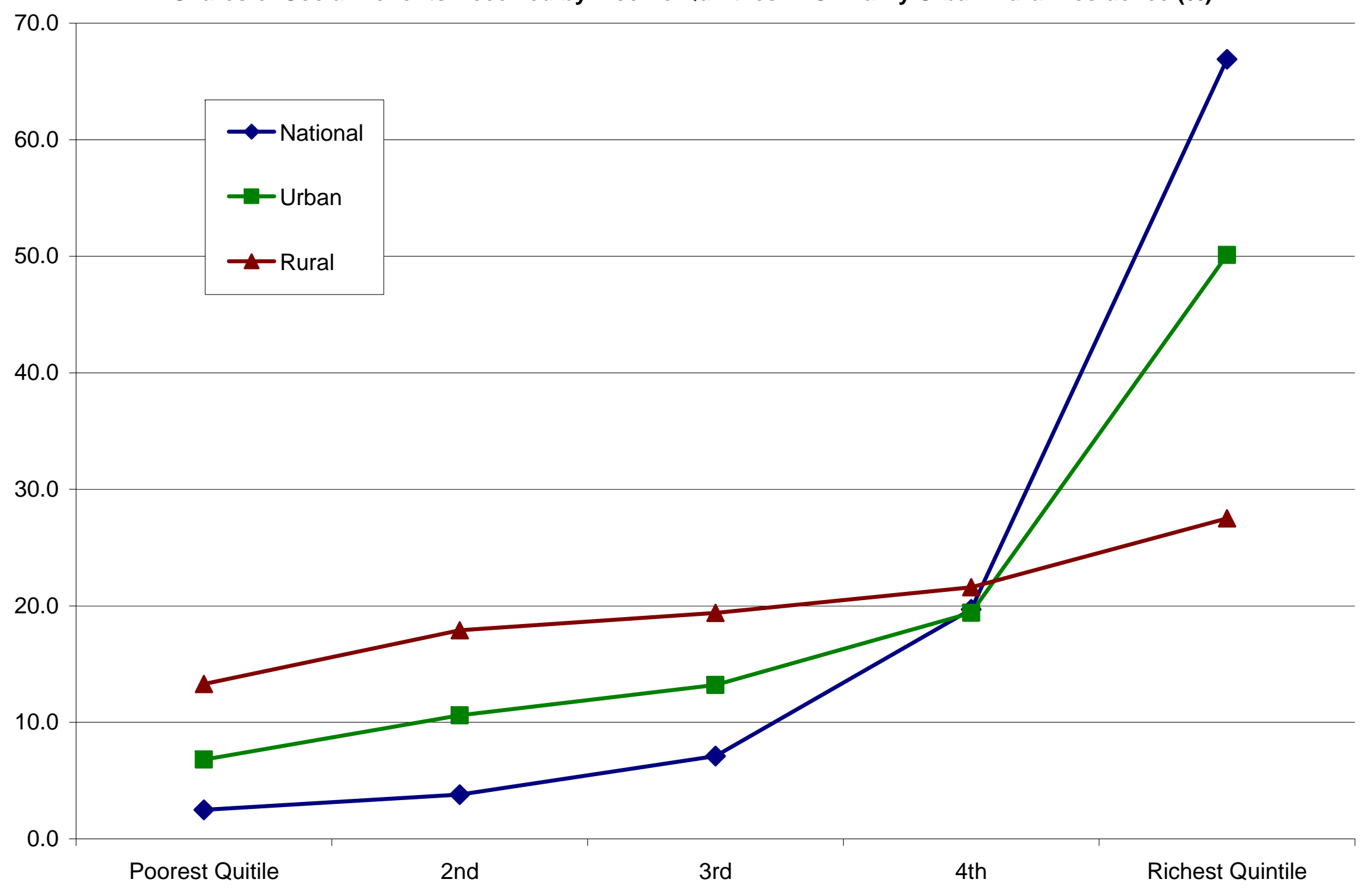


Figure 6: Quintile Shares of Social Benefit Programs in China in 2002

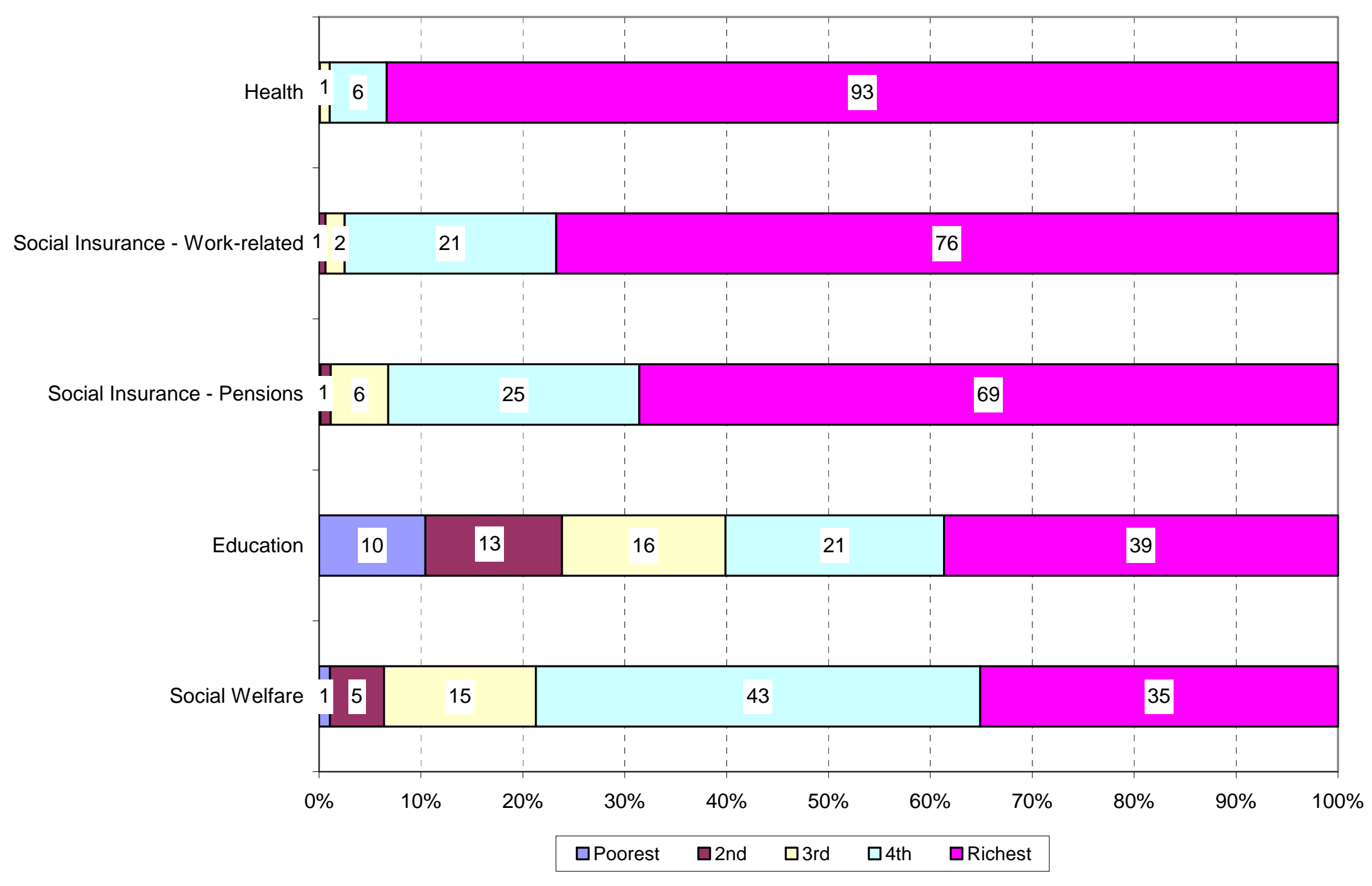


Figure 7: Quintile Shares of Social Benefit Programs in Vietnam in 2004

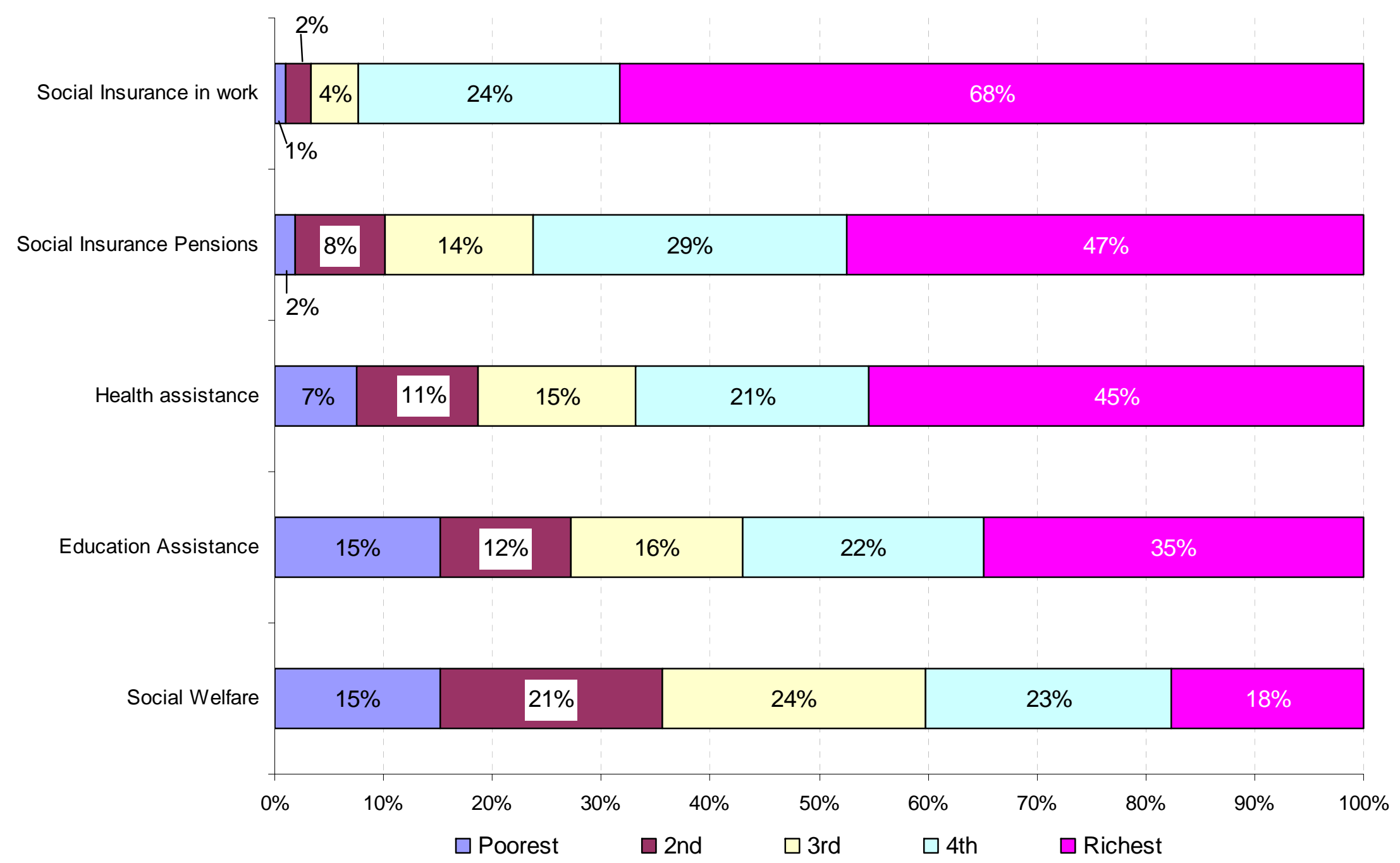

